\title{
The impact of duration of one bout treadmill exercise on cell proliferation and central fatigue in rats
}

\author{
Sang-Won Lee' ${ }^{1}$ Yeon-Soo Kim² , Tae-Won Jun², Jin-Hee Seo ${ }^{3}$, Kijeong Kim ${ }^{4}$, Mal-Soon Shin ${ }^{5}$, Chang-Ju Kim, ${ }^{5, *}$ \\ 'Department of Physical Education, Korea Military Academy, Seoul, Korea \\ ${ }^{2}$ Department of Physical Education, Seoul National University, Seoul, Korea \\ ${ }^{3}$ Division of Sports Science, Baekseok University, Cheonan, Korea \\ ${ }^{4}$ School of Exercise and Sport Science, University of Ulsan, Ulsan, Korea \\ ${ }^{5}$ Department of Physiology, College of Medicine, Kyung Hee University, Seoul, Korea
}

The purpose of this study was to investigate the impact of the duration-dependence of the one bout treadmill exercise on cell proliferation, stress, and central fatigue in rats. The animals were randomly divided into five groups: the non-exercise group, 1-h exercise group, 2-h exercise group, 4-h exercise group, and 6-h exercise group. The exercise load consisted of running at speed of 13 meters $/$ min with the $0^{\circ}$ inclination. Cell proliferation in the hippocampal dentate gyrus was increased in response to one bout moderate treadmill exercise in all exercise groups. But there was no statistical significance between the exercise duration and cell proliferation. The optical density of glucocorticoid (GR)-positive cells in the hippocampal dentate gyrus was not changed by treadmill exercise at any exercise duration. Expressions of serotonin (5-hydroxytryptamine, 5-HT) and tryptophan hyroxylase (TPH) were increased by treadmill exercise only at $6 \mathrm{~h}$ duration. It seemed like that there was no additional benefits on cell proliferation over $2 \mathrm{~h}$ exercise due to stressful factors with over exercise dose, and there was no change of $G R$ expression due to early assessment point of time. It can be suggested that the one-bout of moderate treadmill exercise increased cell proliferation, but treadmill exercise prolonged to $6 \mathrm{~h}$ induced central fatigue in rats.

Keywords: Treadmill exercise, Exercise duration, Cell proliferation, Glucocorticoid receptor, 5-hydroxytryptamine, Tryptophan hyroxylase

\section{INTRODUCTION}

The field of adult neurogenesis was rekindled in 1992, when Reynolds and Weiss showed that precursor cells isolated from the forebrain could differentiate into neurons in vitro (Reynolds and Weiss, 1992). These results and technical advances, including the development of immunocytochemical reagents identifying the phenotype of various neural cells more easily and accurately, led to an explosion of research in this field. Neurogenesis in the olfactory bulb (Tarozzo et al., 1995) and hippocampus (Eriksson et al., 1998) has been well-characterized in the adult mammalian brains nowadays.

It is well known that exercise enhances cell proliferation and/or neurogenesis (Kim et al., 2003; Kim et al., 2004b; Naylor et al.,
2005). In the study of the effects of exercise intensity and duration on neurogenesis, Kim et al. (2003) reported that low-intensity treadmill exercise increased cell proliferation in the hippocampal dentate gyrus more potently compared to the moderate-intensity and high-intensity treadmill exercise, as low-intensity treadmill exercise exerted less stress. Naylor et al. (2005) reported that shortterm wheel running increased cell proliferation, however longterm wheel running resulted in negative effect on cell proliferation because of stress response, and this negative effect of wheel running on cell proliferation was prevented by restricting daily running distance. As a result, running distance and duration of exercise appeared an important factor for enhancing of cell proliferation.

Exercise activates hypothalamic-pituitary-adrenal (HPA) axis
${ }^{*}$ Corresponding author: Chang-Ju Kim

Department of Physiology, College of Medicine, Kyung Hee University,

26 Kyungheedae-ro, Dongdaemun-gu, Seoul 130-701, Korea

Tel: +82-2-961-0407, Fax: +82-2-964-2195, E-mail: changju@khu.ac.kr

Received: October 18, 2013/ Revised: October 21, 2013/ Accepted: October 23, 2013
This is an Open Access article distributed under the terms of the Creative Commons Attribution Non-Commercial License (http://creativecommons.org/licenses/by-nc/3.0/) which permits unrestricted non-commercial use, distribution, and reproduction in any medium, provided the original work is properly cited. 
(Droste et al., 2003), and the most prominent product of HPA axis is cortisol (corticosterone in rodents). High level of glucocorticoids suppressed cell proliferation and adult neurogenesis (Gould et al., 1997; Tanapat et al., 2001), however longer-term elevation of glucocorticoids did not exert this effect (Heine et al., 2004b). In the brain, the actions of glucocorticoids are mediated by two types of adrenal steroid receptors: high-affinity mineralocorticoid receptor (MR) and low-affinity glucocorticoid receptor (GR). MR and GR coexist in the hippocampus. GR is mostly responsible for the neurogenesis. GR agonist dexamethasone inhibited neurogenesis both in vivo and in vitro (Kim et al., 2004a). Furthermore, pharmacological blockades of this receptor have a restorative effect against the glucocorticoids-mediated suppression on cell proliferation (Wong and Herbert, 2005).

In relation to central fatigue, many evidences have suggested that prolonged moderate or exhaustive exercise increased serotonin (5-hydroxytryptamine, 5-HT) synthesis in the various brain regions (Bailey et al., 1993; Lim et al., 2001). Bailey et al. (1993) reported that 5 -HT concentration in the brain was higher at exercise for $1 \mathrm{~h}$ than rest, and increment in 5-HT concentration caused central fatigue. The relation of exercise-induced central fatigue with expressions of 5-HT and tryptophan hyroxylase (TPH), the limiting enzyme for 5-HT synthesis, in the brain has been well documented (Bailey et al., 1993; Lim et al., 2001).

Exercise increases cell proliferation and/or neurogenesis, however, most of studies focused on the impact of exercise intensity using short-duration exercise, less than $2 \mathrm{~h}$. The effects of the duration-dependency of the treadmill exercise on cell proliferation and central fatigue have not been clarified. Thus, we investigated the impact of the duration-dependence of the one bout treadmill exercise on cell proliferation, stress, and central fatigue using rats.

\section{MATERIALS AND METHODS}

\section{Animals and treatments}

Male Sprague-Dawley rats weighing 245 $\pm 10 \mathrm{~g}(\mathrm{n}=20,8$ weeks old) were used. The experimental procedures were performed in accordance with the animal care guidelines of National Institutes of Health (NIH) and Korean Academy of Medical Sciences. All rats were housed under laboratory conditions for one week prior to experiment. The animals were housed under the controlled temperature $\left(20 \pm 2^{\circ} \mathrm{C}\right)$ and maintained in light-dark cycles, each cycle consisting of $12 \mathrm{~h}$ of light and darkness (lights on from 07:00 $\mathrm{h}$ to 19:00 h). Food and water were made available ad libitum.

\section{Experimental design}

The animals were randomly divided into five groups $(\mathrm{n}=8)$ : the control (non-exercise) group, 1-h exercise group, 2-h exercise group, 4-h exercise group, and 6-h exercise group. For adjusting the treadmill exercise, all rats in the exercise groups were forced to walk at speed of 13 meters $/ \mathrm{min}$ with the $0^{\circ}$ inclination during 30 $\mathrm{min}$, for 3 days before the starting experiment. All rats were injected subcutaneously with $50 \mathrm{mg} / \mathrm{kg}$ 5-bromo- 2'-deoxyuridine (BrdU, Sigma Chemical Co., St. Louis, MO, USA), 7 h prior to sacrifice. The rats in the exercise groups were started to walk in order to coincide the sacrifice time. For example, after $1 \mathrm{~h}$ injection, the rats in the 6-h exercise group were forced to walk on treadmill for $6 \mathrm{~h}$. The exercise load consisted of walking at speed of 13 meters/min with the $0^{\circ}$ inclination. This exercise regimen is a moderate-intensity exercise (Kim et al., 2003). The rats in the exercise groups took $10 \mathrm{~min}$ rest and hydration every $50 \mathrm{~min}$ exercise. All rats were sacrificed immediately after finishing exercise.

\section{Tissue preparation}

At the beginning of the sacrificial procedure, the animals were weighed and overdosed with Zoletil $50^{\circledR}(10 \mathrm{mg} / \mathrm{kg}$, i.p.; Vibac Laboratories, Carros, France). After a complete lack of response was observed, the rats were transcardially perfused with $50 \mathrm{mM}$ phosphate-buffered saline (PBS), and fixed with a freshly prepared solution consisting of $4 \%$ paraformaldehyde in $100 \mathrm{mM}$ phosphate buffer ( $\mathrm{PB}, \mathrm{pH}$ 7.4). The brains were dissected and postfixed in the same fixative overnight, and transferred into $30 \%$ sucrose solution for cryoprotection. Serial coronal sections of $40 \mu \mathrm{m}$ thick were made with a freezing microtome (Leica, Nussloch, Germany). Floating sections were stored at $4{ }^{\circ} \mathrm{C}$ until processing for immunohistochemistry.

\section{BrdU immunohistochemistry}

For the detection of newly generated cells in the dentate gyrus, BrdU-specific immunohistochemistry was performed as previously described (Cho et al., 2013; Kim et al., 2013). Five sections on average were selected in each brain region spanning from Bregma $-3.30 \mathrm{~mm}$ to $-4.16 \mathrm{~mm}$. Brain sections were permeabilized by incubation in $0.5 \%$ Triton X-100 in PBS for 20 min, then pretreated in $50 \%$ formamide- $2 \mathrm{X}$ standard saline citrate (SSC) at $65^{\circ} \mathrm{C}$ for $2 \mathrm{~h}$, denaturated in $2 \mathrm{~N} \mathrm{HCl}$ at $37^{\circ} \mathrm{C}$ for $30 \mathrm{~min}$, and rinsed twice in $100 \mathrm{mM}$ sodium borate ( $\mathrm{pH}$ 8.5). Afterwards, the sections were incubated overnight at $4^{\circ} \mathrm{C}$ with $\mathrm{BrdU}$-specific mouse monoclonal antibody (1:600; Roche, Mannheim, Germany). Then the sections were washed three times with PBS and incubated for 
$1 \mathrm{~h}$ with the biotinylated mouse secondary antibody (1:200; Vector Laboratories, Burlingame, CA, USA). Then the sections were incubated for another $1 \mathrm{~h}$ with avidin-peroxidase complex (1:100; Vector Laboratories). For visualization, the sections were incubated in $50 \mathrm{mM}$ Tris- $\mathrm{HCl}$ ( $\mathrm{pH}$ 7.6) containing $0.02 \%$ 3,3'-diaminobenzidine tetrahydrochloride (DAB), $40 \mathrm{mg} / \mathrm{mL}$ nickel chloride, and $0.03 \%$ hydrogen peroxide for $5 \mathrm{~min}$. After BrdU- specific staining, counter-staining was performed on the same sections using a mouse anti-neuronal nucleic (NeuN) antibody (1:300; Chemicon International, Temecula, CA, USA). The sections were washed three times with PBS, incubated for $1 \mathrm{~h}$ with a biotinylated anti-mouse secondary antibody, and processed with VECTASTAIN ${ }^{\circledR}$ Elite ABC Kit (Vector Laboratories). For visualization, the sections were incubated in a reaction mixture consisting of $0.02 \%$ $\mathrm{DAB}$ and $0.03 \%$ hydrogen peroxide for $5 \mathrm{~min}$. The sections were finally mounted onto gelatin-coated slides. The slides were air dried overnight at room temperature, and coverslips were mounted using Permount ${ }^{\oplus}$ (Fisher Scientific Co., Pittsburgh, PA, USA).

\section{Glucocorticoid receptors immunohistochemistry}

For the evaluation of optical density of GR-positive cells in the hippocampal dentate gyrus, GR-specific immunohistochemistry was performed as previously described (Park et al., 2013). Five sections on average were selected in each brain region spanning from Bregma $-3.30 \mathrm{~mm}$ to $-4.16 \mathrm{~mm}$. Free-floating tissue sections were incubated overnight with rabbit anti-GR antibody (Santa Cruz Biotechnology, Santa Cruz, CA, USA) at a dilution of 1:500 for visualization of GR distribution. Then the sections were incubated for $1 \mathrm{~h}$ with anti-rabbit secondary antibody (1:200, Vector Laboratories). The sections were subsequently incubated with an avidin-biotin-peroxidase complex (1:100, Vector Laboratories,) for $1 \mathrm{~h}$ at room temperature. Immunoreactivity was visualized by incubating the sections in a solution consisting of $0.02 \%$ $\mathrm{DAB}$ and $0.03 \%$ hydrogen peroxide in $50 \mathrm{mM}$ Tris- $\mathrm{HCl}(\mathrm{pH} 7.6)$ for approximately $5 \mathrm{~min}$. Then the sections were mounted on gelatin-coated glass slides. The slides were air-dried overnight at room temperature, and coverslips were mounted using Permount $^{\circledast}$ (Fisher Scientific Co.).

\section{5-HT and TPH immunohistochemistry}

For detection of 5-HT-positive and TPH-positive cells in the dorsal raphe, immunohistochemistry was performed as previously described (Seo et al., 2011). Five sections on average were selected in each brain region spanning from Bregma $-7.30 \mathrm{~mm}$ to -8.00 $\mathrm{mm}$. Then the sections were incubated in PBS for $10 \mathrm{~min}$ and washed three times, again with PBS. The sections were then incubated in $1 \%$ hydrogen peroxide for $30 \mathrm{~min}$. Next, the sections were incubated overnight with rabbit anti-5-HT antibody (ImmunoStar, Hudson, WI, USA) at dilution of 1:500 for visualization of 5-HT expression or mouse monoclonal anti-TPH antibody (Calbiochem, Darmstadt, Germany) at a dilution of 1:500 for visualization of TPH expression. Then the sections were incubated for $1 \mathrm{~h}$ with biotinylated anti-rabbit secondary antibody or anti-mouse secondary antibody (Vector Laboratories). The sections were subsequently incubated with avidin-biotin- peroxidase complex (Vector Laboratories) for $1 \mathrm{~h}$ at room temperature. Immunoreactivity was visualized by incubating the sections in a solution consisting of $0.05 \% \mathrm{DAB}$ and $0.01 \%$ hydrogen peroxide in 50 $\mathrm{mM}$ Tris-buffer ( $\mathrm{pH} 7.6)$ for approximately $3 \mathrm{~min}$. Then the sections were mounted on gelatin-coated glass slides. The slides were air-dried overnight at room temperature, and coverslips were mounted using Permount ${ }^{\circledast}$ (Fisher Scientific Co.).

\section{Data analysis}

The area of the granular layer of the hippocampal dentate gyrus was measured using Image-Pro ${ }^{\circledR}$ Plus image analyzer (Media Cybernetics Inc., Silver Spring, MD, USA). The number of BrdUpositive cells were counted hemilaterally and expressed as the number of cells per $\mathrm{mm}^{2}$ of the cross-sectional area of the granular layer of the hippocampal dentate gyrus. The numbers of 5-HT-positive and TPH-positive cells were counted using Image-Pro ${ }^{\circledR}$ Plus image analyzer (Media Cybernetics Inc.) and expressed as the number of cells per section of the dorsal raphe. For assessment of GR immunoreactivity, the staining intensities of the processed sections were assessed in a quantitative fashion according to a microdensitometrical method based on optical density using an image analyzer.

All data were analyzed using the statistical software SPSS (version 14.0). The data were expressed as the mean \pm standard error of the mean (SEM). For the comparison among the groups, oneway ANOVA and Tukey HSD post-hoc test were performed and differences were considered statistical significant at $P<0.05$.

\section{RESULTS}

\section{Cell proliferation in the hippocampal dentate gyrus}

The numbers of BrdU-positive cells in the exercise groups were increased significantly compared to the control group. However, there was no statistic difference among the exercise groups (Fig. 1). The present results showed that cell proliferation in the hippo- 

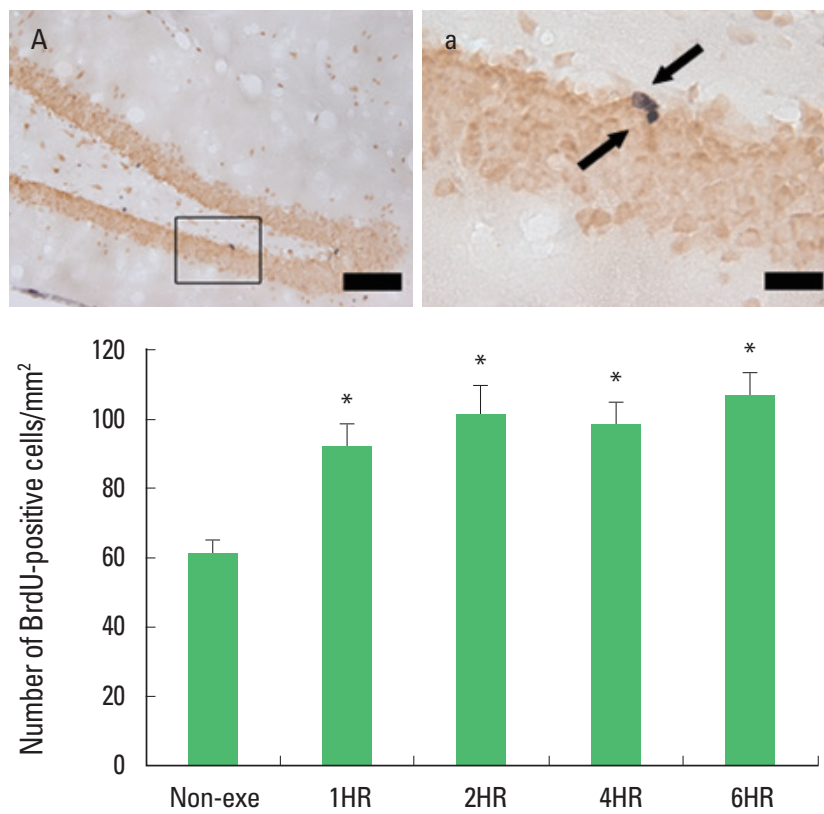

Fig. 1. Duration-dependence of the effect of one bout treadmill exercise on cell proliferation in the hippocampal dentate gyrus. Upper: Photomicrographs of 5-bromo-2'-deoxyuridine (BrdU)-positive cells. Arrows indicate BrdU-positive cells. The scale bar represents $50 \mu \mathrm{m}(\mathrm{A})$ and $25 \mu \mathrm{m}$ (a). Lower: The number of BrdU-positive cells. The data are represented as the mean \pm standard error of the mean (SEM). Non-exe, non-exercise (control) group; $1 \mathrm{HR}, 1$-h exercise group; 2HR, 2-h exercise group; 4HR, 4-h exercise group; 6HR, 6-h exercise group. * represents $P<0.05$ compared to the control group.

campal dentate gyrus was increased significantly in response to one bout treadmill exercise with all of exercise time (from 1 to $6 \mathrm{~h}$ ) $(P<0.05)$. But there was no additional benefit on cell proliferation over $2 \mathrm{~h}$ in one bout treadmill exercise at moderate-intensity.

\section{Expression of GR in the hippocampal dentate gyrus}

The optical density of GR-positive cells in the hippocampal dentate gyrus was not changed by treadmill exercise. There was no significant difference among the exercise groups (Fig. 2). The present results showed that one bout treadmill exercise at any duration exerted no effect on the GR expression in the hippocampal dentate gyrus.

\section{Expressions of 5-HT and TPH in the dorsal raphe}

One bout treadmill exercise in the duration from 1 to $4 \mathrm{~h}$ exerted no significant effect on the 5-HT synthesis in the dorsal raphe. In the 6-h exercise group, 5-HT synthesis in the dorsal raphe was increased significantly compared to the control group $(P<0.05)$ (Fig. 3). The present results showed that one bout treadmill exercise until $4 \mathrm{~h}$ did not increased 5-HT synthesis, however one bout
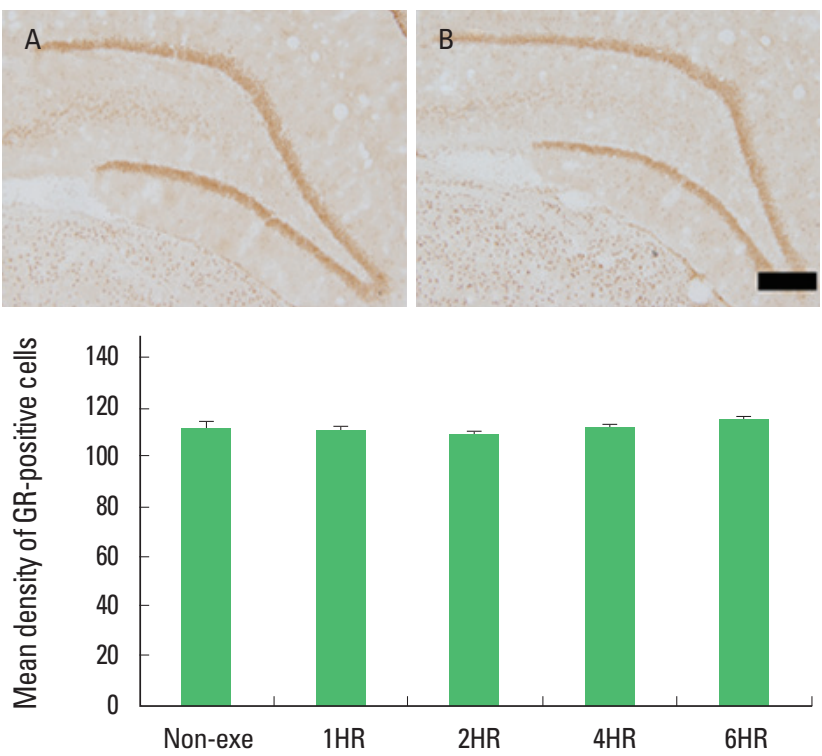

Fig. 2. Duration-dependence of the effect of one bout treadmill exercise on the expression of glucocorticoid receptor (GR) in the hippocampal dentate gyrus. Upper: Photomicrographs of GR-expressing cells. (A) Control group; (B) 6-h exercise group. The scale bar represents $100 \mu \mathrm{m}$. Lower: Optical density of GRpositive cells. The data are represented as the mean \pm standard error of the mean (SEM). Non-exe, non-exercise (control) group; 1HR, 1-h exercise group; 2HR, 2-h exercise group; 4HR, 4-h exercise group; 6HR, 6-h exercise group.

treadmill exercise during $6 \mathrm{~h}$ increased 5-HT synthesis.

One bout treadmill exercise in the duration from 1 to $4 \mathrm{~h}$ exerted no significant effect on the TPH expression in the dorsal raphe. In the 6-h exercise group, TPH expression in the dorsal raphe was increased significantly compared to the control group $(P<0.05)$ (Fig. 4). The present results showed that one bout treadmill exercise until $4 \mathrm{~h}$ did not increased TPH expression, however one bout treadmill exercise during $6 \mathrm{~h}$ increased TPH expression.

\section{DISCUSSION}

Holmes et al. (2004) reported that daily running activity was positively correlated with cell proliferation and cell survival. In the present results, the number of BrdU-positive cells was increased until $2 \mathrm{~h}$, after then there was no more increment till $6 \mathrm{~h}$ (Fig. 1). So there was no dose-dependent tendency between exercise dose and cell proliferation. Ra et al. (2002) reported that forced swimming prolonged more than $5 \mathrm{~min}$ had no additional increment of cell proliferation due to the stress factors. Over-dose of exercise might induce higher levels of corticosterone synthesis and thus counteracted the beneficial effect of exercise on cell proliferation (Kim et al., 2003; Naylor et al., 2005). 

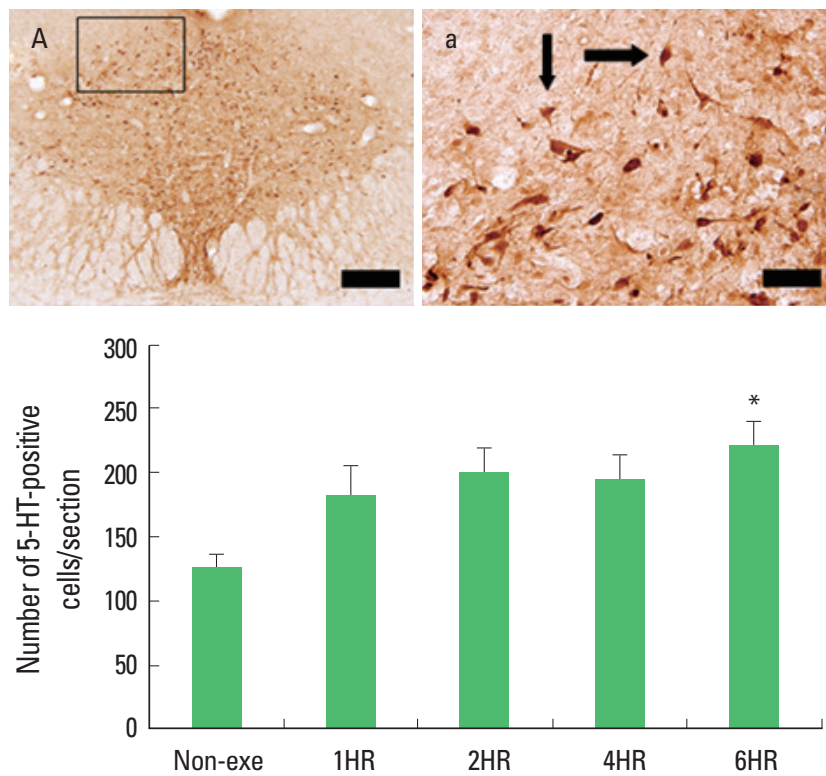

Fig. 3. The effect of one bout treadmill exercise on 5-hydroxytriptamine (5-HT) expression in the dorsal raphe. Upper: Photomicrographs of 5-HT-positive cells. Arrows indicate 5-HT-positive cells. The scale bar represents $100 \mu \mathrm{m}(\mathrm{A})$ and $25 \mu \mathrm{m}$ (a). Lower: The number of 5-HT-positive cells. The data are represented as the mean \pm standard error of the mean (SEM). Non-exe, non-exercise (control) group; 1HR, 1-h exercise group; 2HR, 2-h exercise group; 4HR, 4-h exercise group; 6HR, 6-h exercise group. * represents $P<0.05$ compared to the control group.

The HPA axis is one of the primary stress systems and an integrated neural and endocrine system that plays a key role in releasing the glucocorticoids. Stress, induced by psychological and/or physical, activates the HPA axis and increases the secretion of glucocorticoids (Gould et al., 1997), and raised level of glucocorticoids suppresses proliferation of progenitor cells in the hippocampal dentate gyrus (Tanapat et al., 2001). Stress might prevent progenitors from cell cycle reentry by elevated levels of p27Kip1, an endogenous cell cycle inhibitor (Heine et al., 2004a). Considering these reports, the inhibiting factors (glucocorticoids and p27Kip1) on cell proliferation might be augmented gradually as increasing exercise time, and then cell proliferation of progenitors might be suppressed through accumulated effects of those factors. Thus it seemed like that the suppression on cell proliferation was initiated after $2 \mathrm{~h}$ in the present study.

GR expression underlies a feedback regulation, linking it tightly to the level of the glucocorticoids (Kalman and Spencer, 2002). Under the stressful situation, hippocampal GRs or their mRNA were down-regulated (Kitraki et al., 1999). In the present study, the optical density of GR-positive cells in the hippocampal dentate gyrus at any exercise time was not changed compared to the
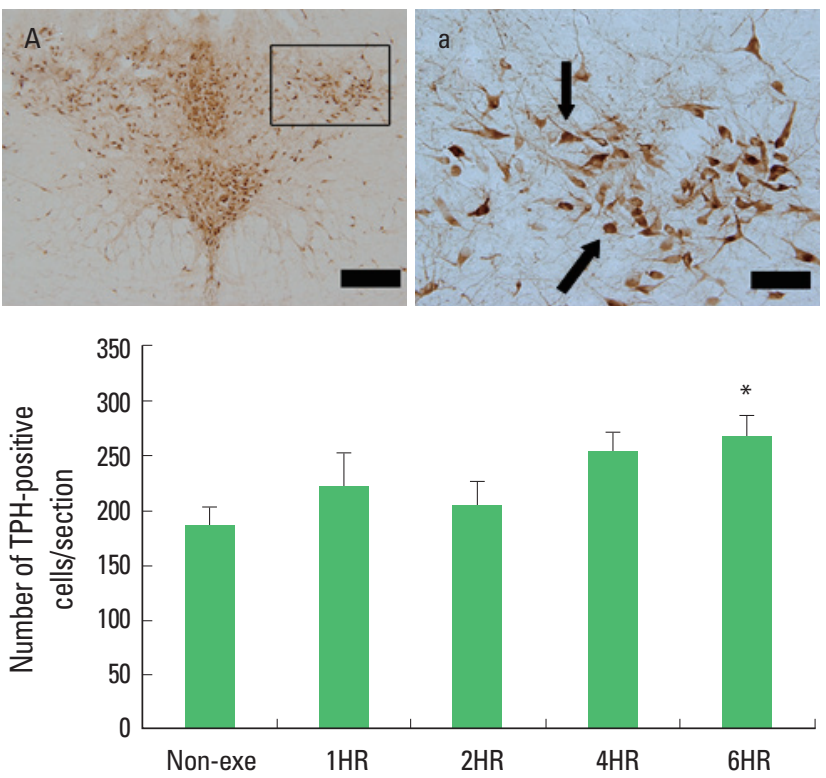

Fig. 4. The effect of one bout treadmill exercise on tryptophan hydroxylase (TPH)-positive cells in the dorsal raphe. Upper: Photomicrographs of TPH-positive cells. Arrows indicate TPH-positive cells. The scale bar represents $100 \mu \mathrm{m}$ (A) and $25 \mu \mathrm{m}$ (a). Lower: The number of TPH-positive cells. The data are represented as the mean \pm standard error of the mean (SEM). Non-exe, non-exercise (control) group; 1HR, 1-h exercise group; 2HR, 2-h exercise group; 4HR, 4-h exercise group; 6HR, 6-h exercise group. * ${ }^{*}$ represents $P<0.05$ compared to the control group.

non-exercise group (Fig. 2). Considering the relation between exercise dose and glucocorticoids secretion, the plasma level of glucocorticoids might be increased. Regulation of GR mRNA and GR protein by glucocorticoids was dose- and time-dependent in vitro (Burnstein et al., 1990; Oalkey and Cidlowski, 1993) and in vivo (Hügin-Flores et al., 2004). Hügin-Flores et al. (2004) reported that a progressive decrement of GR mRNA in the hippocampus was related with increasing doses of corticosterone. Low plasma corticosterone level could require longer time to attain a critical number of activated receptors in the nucleus, so quantitatively significant changes in corticosteroid receptor mRNAs would appear later. Thus, the effect of corticosterone on GR mRNA in the hippocampus can be considered as dose- and time-dependent. In the present experiment, no change of GR expression with exercise prolonged to $6 \mathrm{~h}$ might be occurred due to relative low level of glucocorticoids which could not induce the significant alteration of GR expression at the time of ceasing exercise. However, the level of glucocorticoids secreted with one bout of $6 \mathrm{~h}$ exercise might not be a dose enough to down-regulate GR expression. In the present study, the change of GR expression was not occurred with $6 \mathrm{~h}$ exercise, however the level of glucocorticoid might be 
sufficient to suppress cell proliferation.

Most of the cell bodies of the serotonergic neurons in the brain arise from the dorsal raphe, and then they send projections to diverse target regions including the limbic system, hypothalamus, striatum, and cerebral cortex (Jacobs and Azmitia, 1992). So we investigated the expressions of 5-HT and TPH in the dorsal raphe to evaluate the effects of exercise on central fatigue. We found that both 5-HT and TPH expressions were increased gradually in response to exercise time. Increments of 5-HT and TPH expressions were detected only at $6 \mathrm{~h}$ exercise but not until $4 \mathrm{~h}$ exercise (Figs. $3,4)$. These results mean that moderate exercise induced central fatigue by accumulated effect of prolonged exercise time.

The number of BrdU-positive cells in the hippocampal dentate gyrus was increased in response to one bout moderate treadmill exercise in all exercise groups. However, after $2 \mathrm{~h}$, there was no more increase till $6 \mathrm{~h}$. Expressions of 5-HT and TPH in the dorsal raphe were increased only in the $6 \mathrm{~h}$ exercise group. Based on the present results, one-bout of treadmill exercise at moderate intensity increased cell proliferation, meanwhile treadmill exercise prolonged to $6 \mathrm{~h}$ induced central fatigue in rats.

\section{CONFLICT OF INTEREST}

No potential conflict of interest relevant to this article was reported.

\section{ACKNOWLEDGMENTS}

This work was supported by the National Research Foundation of Korea Grant funded by the Korean Government (NRF-20100022895).

\section{REFERENCES}

Bailey SP, Davis JM, Ahlborn EN. Neuroendocrine and substrate responses to altered brain 5-HT activity during prolonged exercise to fatigue. J Appl Physiol 1993;74:3006-3012.

Burnstein KL, Jewell CM, Cidlowski JA. Human glucocorticoid receptor cDNA contains sequences sufficient for receptor down-regulation. J Biol Chem 1990;265:7284-7291.

Cho HS, Shin MS, Song W, Jun TW, Lim BV, Kim YP, Kim CJ. Treadmill exercise alleviates short-term memory impairment in 6-hydroxydopamine-induced Parkinson's rats. J Exer Rehabil 2013;9:354-361.

Droste SK, Gesing A, Ulbricht S, Müller MB, Linthorst AC, Reul JM. Effects of long-term voluntary exercise on the mouse hypothalamic-pi- tuitary- adrenocortical axis. Endocrinology 2003;144:3012-3023.

Eriksson PS, Perfilieva E, Björk-Eriksson T, Alborn AM, Nordborg C, Peterson DA, Gage FH. Neurogenesis in the adult human hippocampus. Nat Med 1998;4:1313-1317.

Gould E, McEwen BS, Tanapat P, Galea LA, Fuchs E. Neurogenesis in the dentate gyrus of the adult tree shrew is regulated by psychosocial stress and NMDA receptor activation. J Neurosci 1997;17:2492-2498.

Heine VM, Maslam S, Joëls M, Lucassen PJ. Increased P27KIP1 protein expression in the dentate gyrus of chronically stressed rats indicates G1 arrest involvement. Neuroscience 2004a;129:593-601.

Heine VM, Maslam S, Joëls M, Lucassen PJ. Suppressed proliferation and apoptotic changes in the rat dentate gyrus after acute and chronic stress are reversible. Eur J Neurosci 2004b;19:131-144.

Holmes MM, Galea LA, Mistlberger RE, Kempermann G. Adult hippocampal neurogenesis and voluntary running activity: Circadian and dose-dependent effects. J Neurosci Res 2004;76:216-222.

Hügin-Flores ME, Steimer T, Aubert ML, Schulz P. Mineralo- and glucocorticoid receptor mRNAs are differently regulated by corticosterone in the rat hippocampus and anterior pituitary. Neuroendocrinology 2004;79:174-184.

Jacobs BL, Azmitia EC. Structure and function of the brain serotonin system. Physiol Rev 1992;72:165-229.

Kalman BA, Spencer RL. Rapid corticosteroid-dependent regulation of mineralocorticoid receptor protein expression in rat brain. Endocrinology 2002;143:4184-4195.

Kim CH, Lee SC, Shin JW, Chung KJ, Lee SH, Shin MS, Baek SB, Sung $\mathrm{YH}, \mathrm{Kim} \mathrm{CJ}$, Kim KH. Exposure to music and noise during pregnancy influences neurogenesis and thickness in motor and somatosensory cortex of rat pups. Int Neurourol J 2013;17:107-113.

Kim JB, Ju JY, Kim JH, Kim TY, Yang BH, Lee YS, Son H. Dexamethasone inhibits proliferation of adult hippocampal neurogenesis in vivo and in vitro. Brain Res 2004a;1027:1-10.

Kim YP, Kim H, Shin MS, Chang HK, Jang MH, Shin MC, Lee SJ, Lee HH, Yoon JH, Jeong IG, Kim CJ. Age-dependence of the effect of treadmill exercise on cell proliferation in the dentate gyrus of rats. Neurosci Lett 2004b;355:152-154

Kim YP, Kim HB, Jang MH, Lim BV, Kim YJ, Kim H, Kim SS, Kim EH, Kim CJ. Magnitude- and time-dependence of the effect of treadmill exercise on cell proliferation in the dentate gyrus of rats. Int J Sports Med 2003;24:114-117.

Kitraki E, Karandrea D, Kittas C. Long-lasting effects of stress on gluco -corticoid receptor gene expression in the rat brain. Neuroendocrinology 1999;69:331-338

Lim BV, Jang MH, Shin MC, Kim HB, Kim YJ, Kim YP, Chung JH, Kim H, Shin MS, Kim SS, Kim EH, Kim CJ. Caffeine inhibits exercise-induced 
increase in tryptophan hydroxylase expression in dorsal and median raphe of Sprague-Dawley rats. Neurosci Lett 2001;308:25-28.

Naylor AS, Persson AI, Eriksson PS, Jonsdottir IH, Thorlin, T. Extended voluntary running inhibits exercise-induced adult hippocampal progenitor proliferation in the spontaneously hypertensive rat. J Neurophysiol 2005;93:2406-2414.

Oakley RH, Cidlowski JA. Homologous down regulation of the glucocorticoid receptor: The molecular machinery. Crit Rev Eukaryot Gene Expr 1993;3:63-88.

Park JK, Lee SJ, Oh CS. Treadmill exercise exerts ameliorating effect on isolation-induced depression via neuronal activation. J Exerc Rehabil 2013;9:234-242.

Ra SM, Kim H, Jang MH, Shin MC, Lee TH, Lim BV, Kim CJ, Kim EH, Kim KM, Kim SS. Treadmill running and swimming increase cell proliferation in the hippocampal dentate gyrus of rats. Neurosci Lett 2002; 333: 123-126.

Reynolds BA, Weiss S. Generation of neurons and astrocytes from isolat- ed cells of the adult mammalian central nervous system. Science 1992; 255:1707-1710.

Seo JH, Sung YH, Kim KJ, Shin MS, Lee EK, Kim CJ. Effects of Phellinus linteus administration on serotonin synthesis in the brain and expression of monocarboxylate transporters in the muscle during exhaustive exercise in rats. J Nutr Sci Vitaminol (Tokyo) 2011;57:95-103.

Tanapat P, Hastings NB, Rydel TA, Galea LA, Gould E. (2001). Exposure to fox odor inhibits cell proliferation in the hippocampus of adult rats via an adrenal hormone-dependent mechanism. J Comp Neurol 2001; 437:496-504.

Tarozzo G, Peretto P, Fasolo A. Cell migration from the olfactory placode and the ontogeny of the neuroendocrine compartments. Zoolog Sci 1995;12:367-383.

Wong EY, Herbert J. Roles of mineralocorticoid and glucocorticoid receptors in the regulation of progenitor proliferation in the adult hippocampus. Eur J Neurosci 2005;22:785-792. 